\title{
Trends in intelligent manufacturing research: a keyword co-occurrence network based review
}

\author{
Chenxi Yuan ${ }^{1} \cdot$ Guoyan $\mathrm{Li}^{1} \cdot$ Sagar Kamarthi ${ }^{1} \cdot$ Xiaoning $\operatorname{Jin}^{1} \cdot$ Mohsen Moghaddam ${ }^{1}$ (i)
}

Received: 5 March 2021 / Accepted: 21 November 2021 / Published online: 5 January 2022

(c) The Author(s) 2022

\begin{abstract}
In recent years, driven by Industry 4.0 wave, academic research has focused on the science, engineering, and enabling technologies for intelligent and cyber manufacturing. Using a network science and data mining-based Keyword Co-occurrence Network $(\mathrm{KCN})$ methodology, this work analyzes the trends in data science topics in the manufacturing literature over the past two decades to inform the researchers, educators, industry leaders of knowledge trends in intelligent manufacturing. It studies the evolution of research topics and methods in data science, Internet of Things (IoT), cloud computing, and cyber manufacturing. The KCN methodology is applied to systematically analyze the keywords collected from 84,041 papers published in top-tier manufacturing journals between 2000 and 2020. It is not practically feasible to review this large body of literature through tradition manual approaches like systematic review and scoping review to discover insights. The results of network modeling and data analysis reveal important knowledge components and structure of the intelligent and cyber manufacturing literature, implicit the research interests switch and provide the insights for industry development. This paper maps the high frequency keywords in the recent literature to nine pillars of Industry 4.0 to help manufacturing community identify research and education directions for emerging technologies in intelligent manufacturing.
\end{abstract}

Keywords Keyword co-occurrence network · Industry 4.0 · Intelligent manufacturing · Data science · Machine learning · Artificial intelligence

\section{Introduction}

The manufacturing industry has always been significantly influenced by technological revolutions-from the invention of steam engines and electricity to the rise of robotics and automation, the Internet of things (IoT), and cyber-physical systems. The major drivers for integrating these technologies into manufacturing range from traditional performance cri-

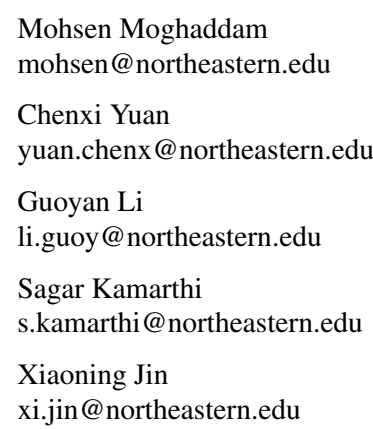

1 Department of Mechanical and Industrial Engineering, Northeastern University, Boston, MA 02115, USA teria such as efficiency, throughput, and cost to emerging criteria like adaptability, resilience, autonomy, interoperability, and cyber-security. With the growing application of intelligent and digital technologies, factories of the future are shaping into networks of cyber-physical machines with embedded sensing, computing, and communication capabilities, enabling adaptive and intelligent automation (Kusiak, 2019; Moghaddam \& Nof, 2017). The scientific and technological advancements (Moghaddam et al., 2018) have enabled emerging paradigms, such as smart manufacturing (Kusiak, 2018; Lu et al., 2016), cyber-physical production systems (Monostori et al., 2016), Industry 4.0 (Oztemel \& Gursev, 2020), and cloud-enabled manufacturing (Chen, 2017). The main objective of this paper is to identified the knowledge components, knowledge structure, and research trends using KCN approach (Duvvuru \& Kamarthi, 2012; Radhakrishnan et al., 2017), which would allow us to explore and analyze a vast amount of literature covering 84,041 papers published in top-tier manufacturing journals between 2000 and 2020. It is not practically feasible to review this many papers through a traditional systematic review process. 


\section{Motivation: technology trends in manufacturing}

The fourth industrial revolution (or Industry 4.0) is driven by the emergence of new technologies such as cyber-physical systems and Internet of Things (IoT) that focus heavily on interconnectivity, automation, machine learning, and realtime analytics. As a result, several paradigms have emerged in recent years to characterize the architectures and requirements for next-generation manufacturing systems:

- Cyber-physical manufacturing lies at the intersection of IoT, cyber-physical systems, and manufacturing science and technologies (Fig. 1), and is generally characterized as "physical and engineered systems whose operations are monitored, controlled, coordinated, and integrated by a computing and communicating core" (Rajkumar et al., 2010). This paradigm advocates capabilities for collecting data accurately and efficiently, analyzing large amounts of data in real-time, making decisions based on real-time data in an instant and distributed manner, and supporting selfconfiguration and self-adaption (Majstorović et al., 2018).

- Industry 4.0 characterizes a new era of industrial revolutions with emphasis on interconnectivity, automation, machine learning, and real-time data analytics (Recommendations for implementing the strategic initiative INDUSTRIE 4.0 April, Securing the future of German manufacturing industry Final report of the Industrie 4.0 Working Group 2013), with the vision of enabling the notion of lot-size of one by addressing current challenges of shortened product lifecycles, growing demand for personalized products, and heightened global competition (Xu, 2012). It is characterized by horizontal integration through supply and value chains, vertical integration of the automation hierarchy and industrial control systems, and end-to-end integration of product and manufacturing engineering throughout their entire value stream (Hofmann \& Rüsch, 2017; Järvenpää et al., 2019).

- Smart manufacturing. This paradigm advocates use of information and communication technologies and advanced data analytics to deal with the uncertain and dynamic behaviors of demand, factory conditions, and supply networks (Thoben et al., 2017). NIST defines smart manufacturing as "fully-integrated, collaborative manufacturing systems that respond in real-time to meet changing demands and conditions in the factory, in the supply network, and in customer needs" (Lu et al., 2016).

- Cloud manufacturing is built upon the technological advances in hardware, virtualization technology, distributed computing, and service delivery over the Internet (Ooi et al., 2018). it is "a new networked manufacturing paradigm that organizes manufacturing resources over networks (manufacturing clouds) according to consumers' needs and demand to provide a variety of on-demand man-

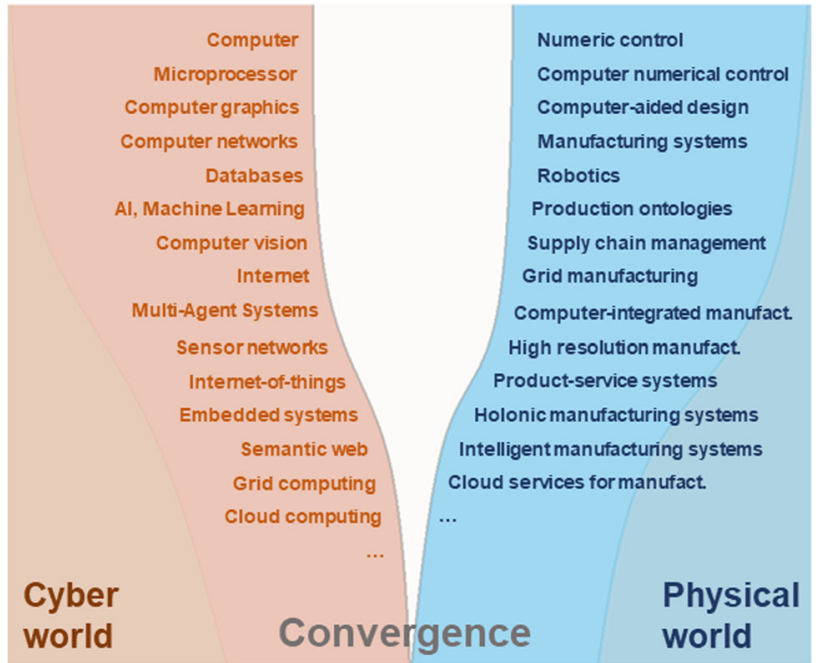

Fig. 1 The convergence of cyber and physical technologies in future manufacturing (adapted from (Monostori et al., 2016))

ufacturing services via networks (e.g., the Internet) and cloud manufacturing service platforms" (Xu., 2012).

Despite the differences between the objectives of the intelligent manufacturing facets mentioned above, their common vernacular is to enable (Moghaddam et al., 2018): (1) integrated and collaborative manufacturing systems and value networks connected via IoT, (2) digitalization and integration of manufacturing resources on the cloud as secure and on-demand services, and (3) connected, intelligent, and autonomous cyber-physical machines enabled by cloud/edge computing and machine learning technologies (Tian et al., 2002). While different segments or domains of the manufacturing industry may have different needs, they are all expected to leverage connectedness and access to real-time insights across systems, processes, partners, products, and people. The goal is to enable mass-customization of products and services; adopt automatic and flexible production lines (Escobar et al., 2021); track parts and products in realtime; facilitate communication among parts, products, and machines; enhance human-machine collaboration(Nguyen Ngoc et al., 2021); achieve IoT-enabled production optimization in smart factories (Yao et al., 2019); create new types of services and business models of interaction in value chains (Alcácer \& Cruz-Machado, 2019); achieve a higher level of intelligent automation; and ultimately increase quality, productivity, flexibility, lower costs, and higher efficiency (Barari et al., 2021).

Figure 1 illustrates the convergence of various cyberphysical manufacturing technologies that collectively aim at materializing the vision of future manufacturing described above. This convergence, in turn, is leading to the development of new knowledge and methods at the intersection of 
the physical world technologies (e.g., robotics, automation, product-service systems, cloud manufacturing) and the cyber world technologies (e.g., AI, machine learning, multi-agent systems, cloud computing). As the emerging cyber-physical manufacturing technologies grow more complex and more knowledge-intensive, the workforce is expected to be adept at handling these technologies. For example, big data analytics and management (e.g., data mining, data classification, data storage) are becoming a critical challenge for manufacturers (Choudhary et al., 2009) (Yao et al., 2019). New cloud architectures and services are needed for analyzing data under certain security and privacy protocols(Alam \& Saddik, 2017). New machine learning algorithms and cloud services are required for optimizing manufacturing processes and systems (Usuga Cadavid et al., 2020). The rise of deep learning poses new opportunities and challenges for manufacturers to decode the increasingly complex manufacturing processes and large-scale production systems to be competitive in their rapidly changing industry (Miškuf \& Zolotová, 2016; Oztemel \& Gursev, 2020). In this context, both researchers and practitioners need to identify emerging research trends, technologies, and workforce knowledge requirements. This is the focal issue investigated in this paper.

\section{Objectives}

This paper is motivated by an urgent need for observing the research trends in rapidly changing interelligent manufacturing landscape(Radhakrishnan et al., 2017). We conducted a systematic review of 84,041 recent articles published in leading journals ranked Q1 by the Scimago Journal \& Country Rank (SJR). A Keyword Co-occurrence Network (KCN) methodology (Duvvuru \& Kamarthi, 2012; Radhakrishnan et al., 2017) to identify knowledge components, knowledge structure, and research trends associated with emerging cyber-physical manufacturing technology areas including the items listed in Fig. 1 and beyond. A KCN is created by treating the keywords of the articles as individual nodes and each co-occurrence of a pair of keywords is modeled as a link between their respective nodes. The co-occurrence frequency of each pair of keywords is represented as the weight of the link connecting the pair. The proposed $\mathrm{KCN}$ methodology is implemented on the keywords listed in the 84,041 articles to obtain key topological parameters and perform a statistical and visual analysis of the network to reveal potential patterns and evolution of keywords, providing insight into the emerging knowledge trends in the manufacturing sector.

The remainder of this article is organized as follows. Background Section discusses the background and related work on the identification of emerging knowledge trends and skills requirements in the manufacturing industry. The $\mathrm{KCN}$ Methodology Section introduces the KCN methodology and elaborates on the design of experiments. Results andAnalyses
Section presents the results and analyses of the experiments. Discussion Section discusses the implications of the results for identifying key knowledge trends and workforce skills requirements in future manufacturing systems. Conclusions Section concludes the article and summarizes the findings and directions for future research.

\section{Background}

This section presents a review of existing studies that investigate various aspects of technologies in cyber-physical manufacturing in a systematic fashion. The current literature reviews are grouped into two categories: (1) concepts and technology trends, and (2) applications and future trends.

Concepts and Technology Trends The articles in this category investigate the key technologies for cyber-physical manufacturing from diverse perspectives. DeFelice and Petrillo (2018) conduct a literature review on smart manufacturing using a multicriteria decision model. They identify cyber-physical systems, IoT, and big data as the most frequently used terms in smart manufacturing based on a large number of publications in years 2014-2016. Alcacer and Cruz-Machado (2019) present a literature review of new technologies for manufacturing systems and conclude that Industry 4.0 has accelerated the progress of manufacturing digitalization. Henzel and Herzwurm (2018) identify cloud manufacturing as an emerging technology by delivering a state-of-the-art survey of current issues on cloud manufacturing. Franco and Ganga (2020) explore additive manufacturing as an emerging technology for manufacturing, describe the framework for additive manufacturing, and explore the effects of adopting additive manufacturing. Big data analytics is essential for generating the digital twins of manufacturing equipment, and subsequently, enabling advanced predictive capacity to identify events that can affect production before they occur (Schuh et al., 2017). Shrouf and Ordiers (Shrouf et al., 2014) define the main characteristics of smart factories with the focus on sustainability. They anticipate IoT to play a major role in manufacturing.

Cyber-physical manufacturing requires advanced analytical capabilities for manufacturers to turn data into insights and decisions in real-time to achieve the required level of adaptability for efficient and personalized production, where big data is targeted as an essential technology (Mourtzis et al., 2016).

Applications and Future Trends Several researchers have explored applications of key technologies and potentials of characterizing next-generation cyber-physical manufacturing systems. Cui and Cara (2020) present a systematic literature review on big data analytics in manufacturing and identify six key drivers: system integration, data, prediction, sustainability, resource sharing, and hardware. They 
identify five potential directions for big data research in manufacturing: modeling and simulation, connectivity and interoperability, standardized big data platform design, realtime big data analytics, and cybersecurity. Baroroh and Wang (2020) conduct a systematic review of recent applications of augmented reality in smart manufacturing from the human-machine interaction perspective and discuss how augmented reality works as an interface between human and artificial intelligence to assist manual operations in manufacturing. Xu and $\mathrm{He}$ (2014) conduct a survey of current research of the Internet of things, which refers to a system of integrated devices (e.g., machines, equipment, sensors, terminals) equipped with sensing, identification, processing, communication, and networking capabilities. IoT is believed to be developed in inventory and production management and transportation. Vaidya and Ambad (2018) present an overview of Industry 4.0 and the state of current manufacturing systems. They impose the issues and challenges of cyber-physical manufacturing including cybersecurity, modularized and flexible physical artifacts, manufacturing systems ensuring high quality and data integrity. Comprehensive systematic reviews have also been conducted to identify opportunities for research in artificial intelligence applications in manufacturing (Aggour et al., 2019; Kutschenreiter-Praszkiewicz, 2008; Nti et al., 2021).

This study addresses the pressing need for an exhaustive review of emerging manufacturing technologies and their impact on the manufacturing workforce in terms of the new domain knowledge and skills required. We speculate that the scientific research publications are representative of technology and skills requirements trends in the broader area of manufacturing science and engineering. Thus, this paper conducts a comprehensive analysis of keywords of Q1 articles in JSR's category of Manufacturing and Industrial Engineering to reach this end.

\section{The KCN methodology}

This section provides a detailed description of the Keywork Co-occurrence Network (KCN) methodology, including the underlying rationale for conducting this type of analysis, data collection and processing procedure, and network parameters for extracting insights on emerging technologies and skills requirements.

\section{Rationale}

Two main network-based methods have been widely used for the review of scientific and technical publications ( $\mathrm{Li}$ et al., 2016). The first is the citation network, which identifies important academic articles according to citation frequency, and focuses on studying the structure of scientific communi- cation by analyzing links between citations in the literature during a short period (Onel et al., 2011) (Shibata et al., 2011). This method is not suitable for the purpose of current work, because it focuses on the relative impact of published scientific work rather than on the emerging technology trends. The other frequently used method is keyword network analysis (KCN) (Su \& Lee, 2010), which explores the links between keywords in the literature to reveal the knowledge components and structure of a scientific field. Keywords can provide a concise overview of the important content and key points of a body of articles as an essential textual element (Li et al., 2016). The KCN methodology captures the connections between different concepts at a micro-level and provides insights about respective roles and importance. Further, the KCN methodology can deliver network attributes on articles published over a long period and hence reveal the evolution of the topics over time (Zhong et al., 2014). Therefore, this paper applies the concept of KCN to analyze the linkage of concepts and investigate the research topics, their relationships, and development trends in manufacturing science and engineering. The rationale behind the KCN methodology is that the keywords of top-tier, peer-reviewed journal articles represent the most important areas of research and development in their respective area of study and that their co-occurrence represents their relationships and relative importance. This technique can analyze the content of a large number of papers by quantifying the associations between keywords, reflecting on the respective role and evolution of keywords, and identify the overall structure of the research field (Lozano et al., 2019).

\section{Data collection and processing procedure}

To build the KCN for manufacturing science and engineering, we collected the keywords of top-tier journals published in the period betwen2000 and 2019 in 43 journals that are ranked as SJR Q1 (Table 1). All papers published in each journal were accessed through the Web of Science database and the author-specified keywords from all these articles were collected for further processing. A total of 84,041 articles were identified, which collectively comprise a total of 258,882 standard keywords defined by their authors (Table 2). The number of publications increased from 1638 papers in 2,000 to 7,887 papers in 2019 . These keywords were reconciled to eliminate redundancy, by unifying singular and plural variants (e.g., "algorithms" and "algorithm"), hyphened and non-hyphenated phrases (e.g., "multi agent system" and "multi-agent system"), synonyms (e.g., "statistical methods" and "statistical modeling"), and acronym variants (e.g., "artificial neural networks (ANN)", "artificial neural networks", and "ANN"). Next, keywords relevant to the cyber-world and physical-world manufacturing science, engineering, and technology were selected by three authors knowledgeable 
Fig. 2 The procedure of data collection, processing and cleaning

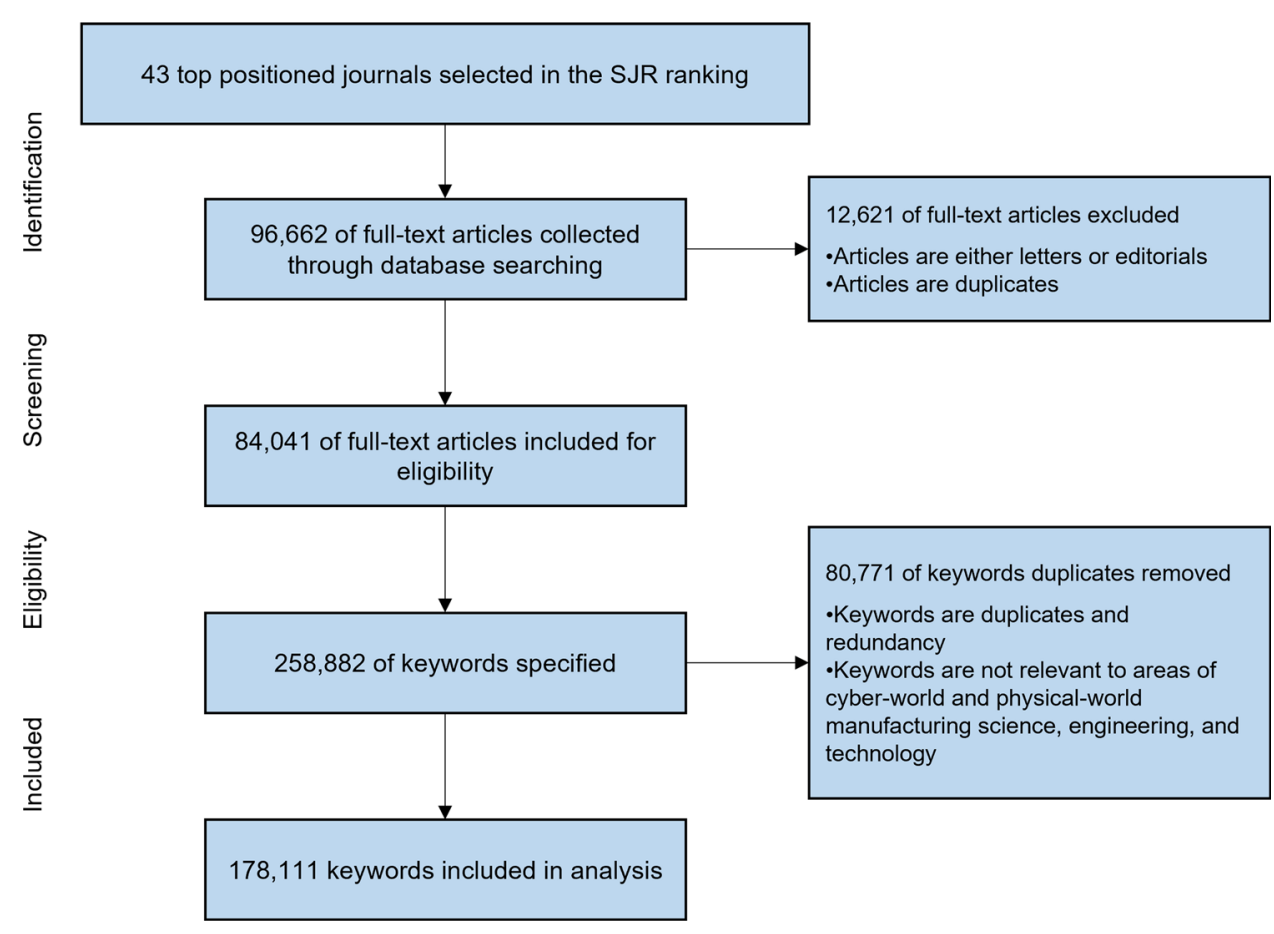

about these areas. The selection of keywords by three authors was compiled into the final keyword list with 178,111 keywords in total. Through this process, the keywords that had occurred with high frequency but were irrelevant to cyber-physical manufacturing technologies were eliminated. Co-occurrence of all pairs of keywords was then calculated by counting the co-appearance of word-pairs in all the papers. The procedure of data collection, processing and cleaning are described in Fig. 2.

The papers published between 2000 and 2019 were partitioned into four 5-year windows: 2000-2004, 2005-2009, 2010-2014, and 2015-2019. A separate KCN is constructed for each window to explore the temporal evolution of the trends in manufacturing science and engineering research. The attributes of the KCNs are then imported into the Network Workbench software (NWB Team, 2006) to retrieve various network parameters to explore co-occurrence patterns among keywords, and then generate insights on the potential knowledge structure of the emerging trends in manufacturing.

\section{Network analysis parameters}

This section describes the network analysis parameters (Radhakrishnan et al., 2017) used in the KCN methodology for analyzing the network connection weights and the relationship between different nodes. The first parameter is degree, which is the total number of links that connect a given node to other nodes in a network. The degree of node $i$ represents its relative importance in the network, as follows:

$k_{i}=\sum_{j \in N} e_{i j}$,

where $N$ denotes the set of all keywords in the keyword network, and $e_{i j} \in\{0,1\}$ denotes the existence of an edge between nodes $i$ and $j(i, j \in N)$. In the KCN methodology, the higher the degree of a node, the greater the centrality of the node in the keyword network. Centrality of a keyword is an indicator of its importance.

The keyword network is a weighted network. The weight $w_{i j}$ of an edge $e_{i j}$ represents the count of nodes $i$ and $j$ cooccurring. The strength of node $i$ is the sum of the weights of all edges connected to node $i$. It is, like centrality, an indicator of the relative importance and connectivity of a keyword in the network. The strength of node $i$ is calculated as follow:

$s_{i}=\sum_{j \in N} e_{i j} w_{i j}$.

Another key parameter for $\mathrm{KCN}$ analysis is the average weight of end point degrees, which measures the cooccurrence of the edges between pairs of nodes as the degrees of the nodes change. It is defined as follows:

$w_{i j} \sim\left(k_{i} k_{j}\right)$

where $k_{i}$ and $k_{j}$ are degrees of nodes $i$ and $j$, respectively, and $\langle\cdot\rangle$ denotes average value. In the context of this research, the 
Table 1 List of the selected 43 journals positioned top in the SJR ranking

\begin{tabular}{|c|c|}
\hline $\begin{array}{l}\text { Journal of operations } \\
\text { management }\end{array}$ & CAD Computer Aided Design \\
\hline $\begin{array}{l}\text { International Journal of } \\
\text { Machine Tools \& } \\
\text { Manufacture }\end{array}$ & $\begin{array}{l}\text { Food and Bioprocess } \\
\text { Technology }\end{array}$ \\
\hline $\begin{array}{l}\text { Production and Operations } \\
\text { Management }\end{array}$ & $\begin{array}{l}\text { Journal of Manufacturing } \\
\text { Processes }\end{array}$ \\
\hline Additive Manufacturing & $\begin{array}{l}\text { Industrial Management and } \\
\text { Data Systems }\end{array}$ \\
\hline $\begin{array}{l}\text { International Journal of } \\
\text { Production Economics }\end{array}$ & $\begin{array}{l}\text { CIRP Journal of Manufacturing } \\
\text { Science \& Technology }\end{array}$ \\
\hline $\begin{array}{l}\text { CIRP Annals-Manufacturing } \\
\text { Technology }\end{array}$ & $\begin{array}{l}\text { Materials and Manufacturing } \\
\text { Processes }\end{array}$ \\
\hline $\begin{array}{l}\text { Virtual and Physical } \\
\text { Prototyping }\end{array}$ & $\begin{array}{l}\text { IEEE Transactions on Industry } \\
\text { Applications }\end{array}$ \\
\hline Journal of Quality Technology & Rapid Prototyping Journal \\
\hline $\begin{array}{l}\text { Reliability Engineering and } \\
\text { System Safety }\end{array}$ & $\begin{array}{l}\text { International Journal of } \\
\text { Bioprinting }\end{array}$ \\
\hline Manufacturing Letters & $\begin{array}{l}\text { International Journal of } \\
\text { Advanced Mfg. Technology }\end{array}$ \\
\hline $\begin{array}{l}\text { Journal of Materials Processing } \\
\text { Technology }\end{array}$ & Journal of Process Control \\
\hline $\begin{array}{l}\text { Advanced Materials } \\
\text { Technologies }\end{array}$ & $\begin{array}{l}\text { Journal of Manufacturing } \\
\text { Technology Management }\end{array}$ \\
\hline $\begin{array}{l}\text { Journal of Manufacturing } \\
\text { Systems }\end{array}$ & $\begin{array}{l}\text { Sustainable Production and } \\
\text { Consumption }\end{array}$ \\
\hline $\begin{array}{l}\text { International Journal of } \\
\text { Production Research }\end{array}$ & $\begin{array}{l}\text { Machining Science and } \\
\text { Technology }\end{array}$ \\
\hline $\begin{array}{l}\text { Journal of Industrial } \\
\text { Information Integration }\end{array}$ & $\begin{array}{l}\text { 3D Printing and Additive } \\
\text { Manufacturing }\end{array}$ \\
\hline $\begin{array}{l}\text { Sustainable Materials and } \\
\text { Technologies }\end{array}$ & $\begin{array}{l}\text { Advances in Production } \\
\text { Engineering and Management }\end{array}$ \\
\hline $\begin{array}{l}\text { Production Planning and } \\
\text { Control }\end{array}$ & $\begin{array}{l}\text { Journal of Computing and } \\
\text { Information Science in Eng }\end{array}$ \\
\hline $\begin{array}{l}\text { Robotics and } \\
\text { Computer-Integrated } \\
\text { Manufacturing }\end{array}$ & $\begin{array}{l}\text { International Journal of } \\
\text { Precision Engineering and } \\
\text { Mfg }\end{array}$ \\
\hline $\begin{array}{l}\text { Journal of Intelligent } \\
\text { Manufacturing }\end{array}$ & $\begin{array}{l}\text { International Journal of } \\
\text { Industrial Eng. Computations }\end{array}$ \\
\hline IISE Transactions & Advances in Natural Sciences \\
\hline $\begin{array}{l}\text { Flexible Services and } \\
\text { Manufacturing Journal }\end{array}$ & $\begin{array}{l}\text { Journal of Intelligent and } \\
\text { Robotic Systems }\end{array}$ \\
\hline $\begin{array}{l}\text { Operations Management } \\
\text { Research }\end{array}$ & Advances in Manufacturing \\
\hline
\end{tabular}

average weight of end point degrees answers the following question: Are the connections between high-degree keywords stronger than of the connections between low-degree keywords? This parameter can be approximated by a power-law:

$w_{i j} \sim\left(k_{i} k_{j}\right)^{\theta}$,
Table 2 The total number of papers and keywords each year from 2000 to 2019

\begin{tabular}{llllll}
\hline Year & \# of paper & $\begin{array}{l}\text { \# of } \\
\text { keywords }\end{array}$ & Year & \# of paper & $\begin{array}{l}\text { \# of } \\
\text { keywords }\end{array}$ \\
\hline 2019 & 7887 & 23,704 & 2009 & 4028 & 12,592 \\
2018 & 7552 & 22,781 & 2008 & 3781 & 11,549 \\
2017 & 7082 & 21,687 & 2007 & 3436 & 10,734 \\
2016 & 5859 & 18,288 & 2006 & 3124 & 9349 \\
2015 & 5793 & 18,048 & 2005 & 2537 & 7877 \\
2014 & 5219 & 16,512 & 2004 & 2228 & 6753 \\
2013 & 5203 & 16,116 & 2003 & 2469 & 7377 \\
2012 & 4346 & 13,672 & 2002 & 2379 & 7138 \\
2011 & 3742 & 11,936 & 2001 & 2274 & 6952 \\
2010 & 3464 & 10,803 & 2000 & 1638 & 5014 \\
\hline
\end{tabular}

where the exponent $\theta$ is a positive constant. Positive correlation confirms that highly connected keywords are more likely to have stronger connections.

The next network parameter examined in this study is the average weighted nearest neighbor's degree of node $i$, for all $i \in N$. It measures the tendency of a node to link with its neighbors with similar degree characteristics: high degree nodes connecting with high degree neighbors and low degree nodes connecting with low degree neighbors. This parameter can be calculated as follows:

$k_{i}^{n}=\frac{1}{s_{i}} \sum_{j \in N} e_{i j} w_{i j} k_{j}$

If this value increases with the keyword degrees, it represents the following assortative behavior: high-degree keywords are associated with other high-degree keywords in the papers. Inversely, the disassortative behavior indicates that high-degree keywords co-occur with low-degree keywords.

The final parameter is the weighted clustering coefficient, which measures the local cohesiveness of node $i$ among its neighbors. It represents the importance of the structure clustered around a certain keyword on the basis of the interaction intensity found on the local triplets (Barrat et al., 2004). This parameter is formulated as follows:

$c_{i}=\frac{1}{s_{i}\left(k_{i}-1\right)} \sum_{j, h \in N} \frac{\left(w_{i j}+w_{i h}\right)}{2} e_{i j} e_{i h} e_{j h}$.

A greater $c_{i}$ indicates that keyword $i$ has better connectivity and cohesiveness to other keywords. 
Table 3 Topological characteristics of $\mathrm{KCN}$ for the manufacturing science and engineering literature

\begin{tabular}{lllll}
\hline Characteristics & $2000-2004$ & $2005-2009$ & $2010-2014$ & 2015-2019 \\
\hline Number of nodes & 112 & 134 & 157 & 189 \\
Number of edges & 129 & 221 & 274 & 573 \\
Average degree & 2.3 & 3.3 & 3.49 & 6.06 \\
Maximum degree & 20 & 32 & 34 & 48 \\
Average weight & 1.55 & 1.95 & 1.91 & 1.91 \\
Maximum weight & 24 & 51 & 44 & 29 \\
\hline
\end{tabular}

\section{Results and analyses}

The main topological characteristics of the keyword networks for the four-time windows are presented in Table 3. Over the two decades, the number of keywords increased approximately by $68 \%$, which shows that the knowledge structure in the manufacturing science and engineering literature has experienced a significant expansion by the introduction of new concepts and topics. Over the same period, the number of edges connecting the nodes has dramatically grown by $340 \%$, which implies the significant increase in the co-occurrence of keywords in recent papers relative to the older ones. The growth in the number of edges also reflects increasing synergy between different topics, methods, and concepts. The number of edges in the 2015-2019 time window is two times the number of edges in 2005-2009 or 2010-2014, and almost five times the number of edges in 2000-2004. These observations again indicate rapid growth in both the number of technical concepts and topics as well as their convergence, as they co-occur more frequently in the publications. These observations are also evident from the average degree results (in Table 3), which show the emergence of diverse research topics described by new keywords or old ones that were not extensively discussed in the earlier literature. The average and maximum weight indicate that low-degree nodes in the first decade may have been candidates for further investigation in the second decade and that researchers are working on a combination of emerging and relatively more established concepts and topics.

Table 4 presents the top twenty keywords with the highest strength $\left(s_{i}\right)$ in each time window. It informs which keywords remained dominant or became obsolete over the years. It also points out which keywords have been gaining importance in recent years. The strength of most keywords took a big jump from 2000 to 2004 to 2005-2009 but remained relatively stable until 2010-2015. In 2015-2019, the keyword strengths became three times greater than the strengths in 2000-2004. The close examination of emerging keywords indicates that cyber-physical manufacturing has gained a lot of traction with researchers in 2015-2019. As can be seen, genetic algorithm, optimization, heuristics, fault diagnosis, data mining are the five most frequently used keywords across all time windows in two decades. These keywords describe methods in cyber-physical manufacturing. However, except for the top five keywords, the others shift a lot in their rankings. To better observe the evolution of keywords for the past twenty years, two slope charts are presented in Fig. 3.

Figure 3. shows shifts in the strenght-based ranking of keywords from 2000-2004 to 2015-2019, where a node strength reflects the frequency of its occurrence in the literature. The left side slope-chart with orange line captures the emerging topics, which were ranked low in 2000-2004 but rose to top ranks in 2015-2019, as shown on the right side of the figure with blue line. Three main categories can be defined based on the trends of all keywords in recent two decades, as follows:

- Fundamental topics: It is evident that genetic algorithm, optimization, heuristics, fault diagnosis, and data mining remain in the top five positions throughout the 2000-2019 period, as shown in Fig. 3. These rankings indicate the fundamental role these topics have played in developing intelligent manufacturing research. Thus, these keywords are referred to as fundamental topics in intelligent manufacturing, which still remain active and important areas of research in manufacture.

- Emerging topics: It can be observed from the left side slope-chart that the emerging topics are mostly related to two classes: cyber technologies and data science-oriented topics. The cyber technologies include Industry 4.0, smart manufacturing, cloud manufacturing, Internet of things, augmented reality and digital manufacturing. The data science-oriented topics include machine learning, multiobjective optimization, Bayesian networks, big data, and cloud computing. The emerging keywords project the prospects of intelligent manufacturing research and possibly the future needs of the industry from both technological and workforce perspectives. New technologies and methods, especially those that are data science-oriented, have become the focus of recent research in manufacturing. The emerging topics also underscore important technologies (e.g., prognostics and health management), which are not necessarily"hot topics" like deep learning and augmented reality.

- Maturing topics: The last category of research topics includes keywords that used to be hot topics last decad but their rankings have significantly declined since then. 
Table 4 Top 20 keywords with the highest strength $\left(s_{i}\right)$

\begin{tabular}{|c|c|c|c|c|c|c|c|}
\hline \multicolumn{2}{|l|}{ 2000-2004 } & \multicolumn{2}{|l|}{ 2005-2009 } & \multicolumn{2}{|l|}{ 2010-2014 } & \multicolumn{2}{|l|}{ 2015-2019 } \\
\hline Keyword & $s_{i}$ & Keyword & $s_{i}$ & Keyword & $s_{i}$ & Keyword & $s_{i}$ \\
\hline Genetic algorithm & 227 & Genetic algorithm & 494 & Genetic algorithm & 499 & Optimization & 592 \\
\hline Optimization & 184 & Optimization & 351 & Optimization & 451 & Genetic algorithm & 388 \\
\hline Heuristics & 79 & Heuristics & 152 & Heuristics & 178 & Fault diagnosis & 240 \\
\hline Fault diagnosis & 76 & Neural networks & 133 & Neural networks & 129 & Data mining & 168 \\
\hline Data mining & 59 & Statistical method & 105 & Statistical methods & 120 & Heuristics & 157 \\
\hline Neural networks & 54 & ANOVA & 103 & Fault diagnosis & 119 & $\begin{array}{l}\text { Multi-objective } \\
\text { optimization }\end{array}$ & 142 \\
\hline Statistical methods & 45 & Fault diagnosis & 101 & Model predictive control & 98 & Neural networks & 138 \\
\hline $\begin{array}{l}\text { Computer-aided } \\
\text { manufacture }\end{array}$ & 44 & Data mining & 100 & Data mining & 96 & ANOVA & 119 \\
\hline Expert system & 40 & Image processing & 54 & ANOVA & 95 & Industry 4.0 & 118 \\
\hline Multi-agent systems & 35 & Ant colony optimization & 53 & $\begin{array}{l}\text { Multi-objective } \\
\text { optimization }\end{array}$ & 92 & Statistical methods & 114 \\
\hline ANOVA & 30 & Multi-agent system & 53 & Dynamic programming & 75 & Big data & 113 \\
\hline Model predictive control & 30 & Model predictive control & 51 & Multi-agent systems & 67 & Model predictive control & 112 \\
\hline Mobile robot & 28 & $\begin{array}{l}\text { Multi-objective } \\
\text { optimization }\end{array}$ & 47 & Ant colony optimization & 62 & Cloud manufacturing & 102 \\
\hline Image processing & 28 & Prediction & 42 & $\begin{array}{l}\text { Principal component } \\
\text { analysis }\end{array}$ & 58 & Machine learning & 99 \\
\hline Condition monitoring & 22 & $\begin{array}{r}\text { Computer-aided } \\
\text { manufacturing }\end{array}$ & 42 & Image processing & 54 & Image processing & 97 \\
\hline Linear programming & 21 & Mobile robot & 41 & Prediction & 50 & Smart manufacturing & 85 \\
\hline Case-based reasoning & 21 & Dynamic programming & 38 & Mobile robot & 46 & Condition monitoring & 84 \\
\hline Prediction & 20 & $\begin{array}{l}\text { Principal component } \\
\text { analysis }\end{array}$ & 31 & Support vector machine & 43 & Prediction & 83 \\
\hline Algorithm & 19 & Condition monitoring & 28 & $\begin{array}{l}\text { Condition-based } \\
\text { maintenance }\end{array}$ & 40 & Internet of things & 81 \\
\hline
\end{tabular}

Keywords like expert systems, case-based reasoning, and automated manufacturing systems are examples of topics that have significantly matured over the past two decades and are currently at the backbone of some of the emerging topics in manufacturing. It is observed that most keywords in this category are relatively established manufacturing areas such as computer-aided manufacturing, multi-agent systems, tool wear monitoring, distributed manufacturing, and multisensor fusion. It is worth noting that the descending rankings of these topics only represent their maturity and not lower their importance in practice compared to the new top-ranked technologies in recent years.

Figure 4 shows the probability distribution functions of weights of KCNs for four time periods, where both $x$ and $y$ axes are on a logarithmic scale. It is observed all four periods have the decaying pattern for weight distribution, which indicates that edges with large weights occur with low frequency, and in contrast edges with small weights occur with high frequency. In other words, the number of edges with small weights is significantly larger than the number of edges with large weights. This pattern implies that manufacturing literatures has only a few keywords that co-occur with many other keywords and, in contrast, a large number of keywords that co-occur with only a small set of other keywords.

Figure 5 depicts the average weight of end point degrees. This parameter reflects the correlations between the degrees of end nodes of links. The average edge weights show an exponential increase with the end point degrees. This behavior highlights the increase in the weights of connected hubs. In other words, the keyword hubs (i.e., popular keywords) occur in multiple articles dealing with different topics. The average weight of end point degrees in the keyword network for each period increases sharply for values of $k_{i} k_{j}>10^{2}$, which indicates that the tendency of co-occurrence increases sharply for high degree keywords. Except for the 2015-2019 period (red plot in Fig. 5), most of the weights of 2000-2004, 2005-2009, and 2010-2014 were found to be close to one, which indicates the presence of a diverse set of keywords that are decentralized, whereas only a few being the hubs. 


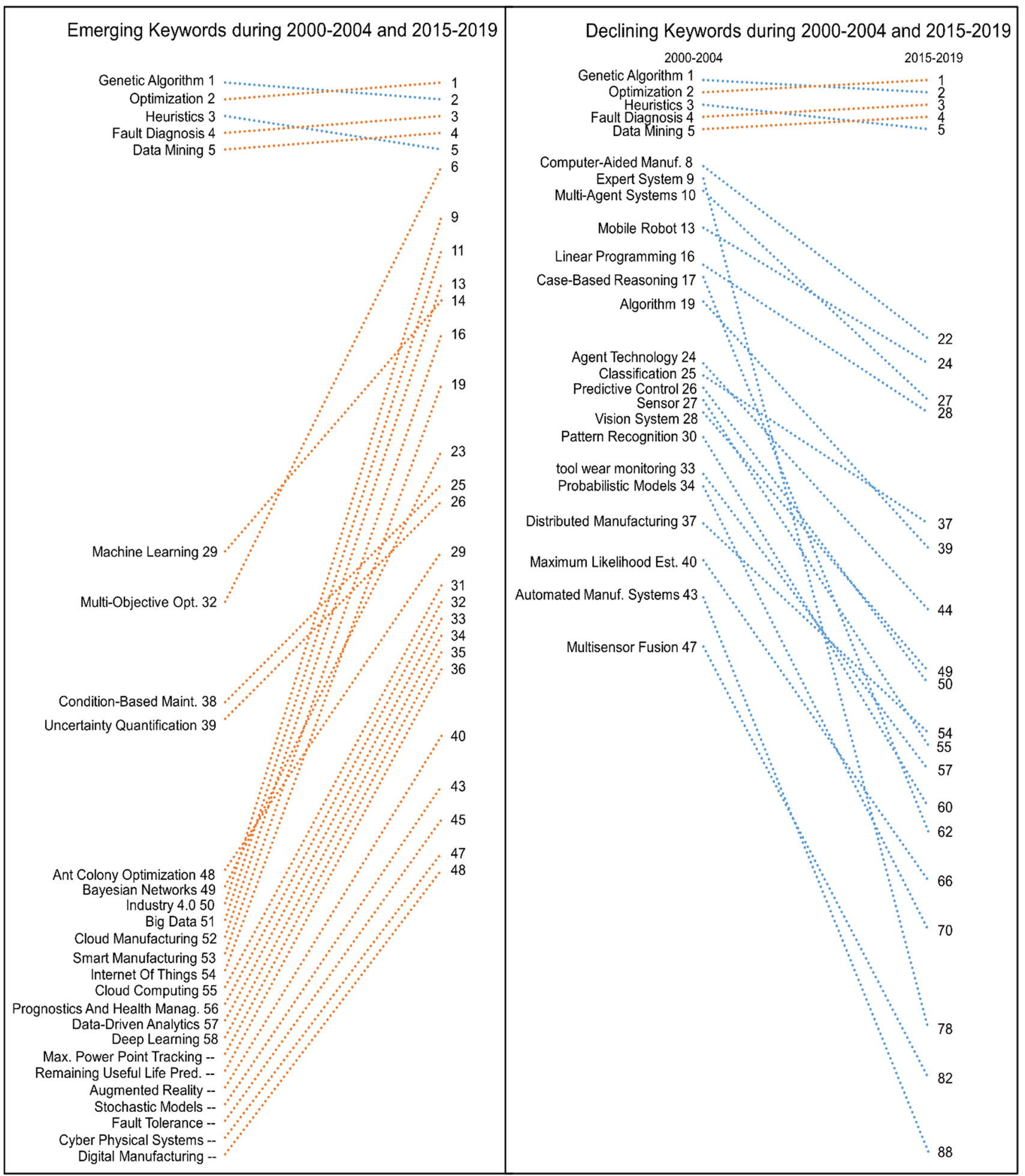

Fig. 3 Emerging keywords (left-side panel) and declining keywords (right-side panel) during 2000-2004 and 2015-2019. The number next to the keyword indicate the ranking based on the keyword strength

Figure 6 indicates the behavior of the average weighted nearest-neighbor degrees. As observed, $\left\langle w_{i j}\right\rangle$ almost remained constant for two decades. The slight variation in the trends of the four-time windows shows an uncorrelated structure, which implies that there are correlations among different-degree keywords and that high-degree keywords 


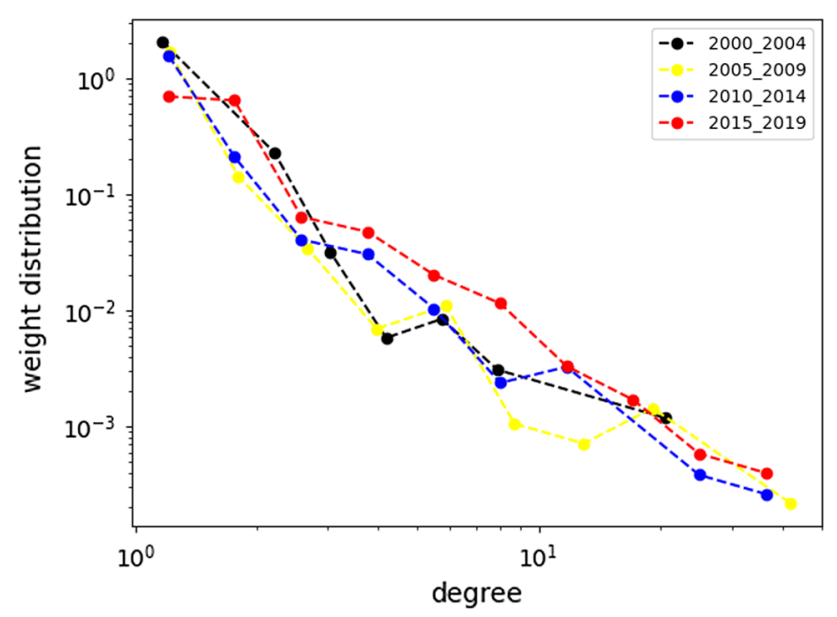

Fig. 4 Weight distribution of KCNs for the manufacturing science and engineering literature

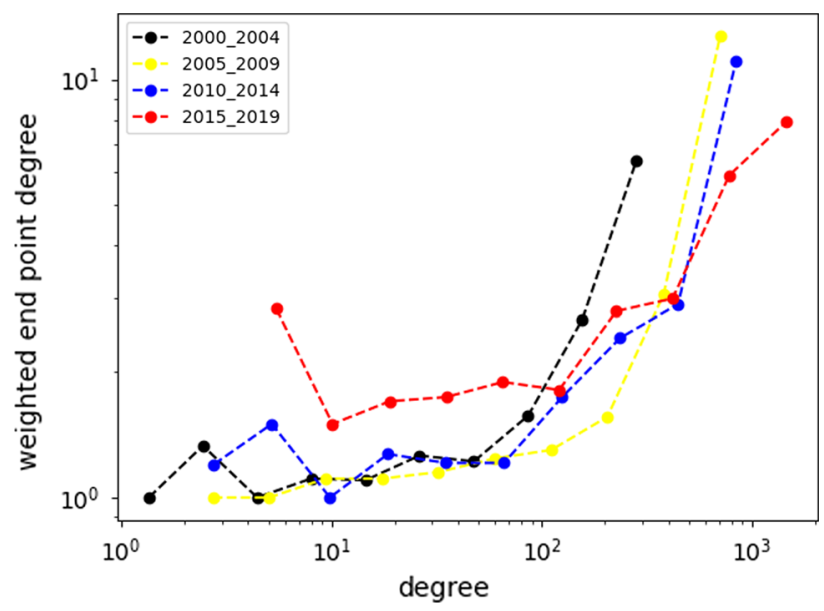

Fig. 5 Weighted end point degree of $\mathrm{KCN}$ keywords for the manufacturing science and engineering literature

tend to link up with not only other high-degree keywords but also with low-degree keywords.

Figure 7 shows the plot of weighted clustering coefficient versus degree. The continuously decaying coefficients indicate that keywords with high degree present a much lower clustered neighborhood than low-degree keywords. Keywords with low degree co-occur within well-defined keyword groups (i.e., high clustering). In contrast, keywords with high degrees co-occur with different groups and communities, implying that keywords with larger degrees are connected to several keywords that do not form cohesive groups within themselves. Moreover, it is observed that the trend line in 2015-2019 is in general above the trend lines for other time windows. It implies that high-degree keywords in recent papers tend to connect with relatively a large number of keywords within interconnected groups.

In summary, the KCN perameters combining the topological information with the weight distribution of networks

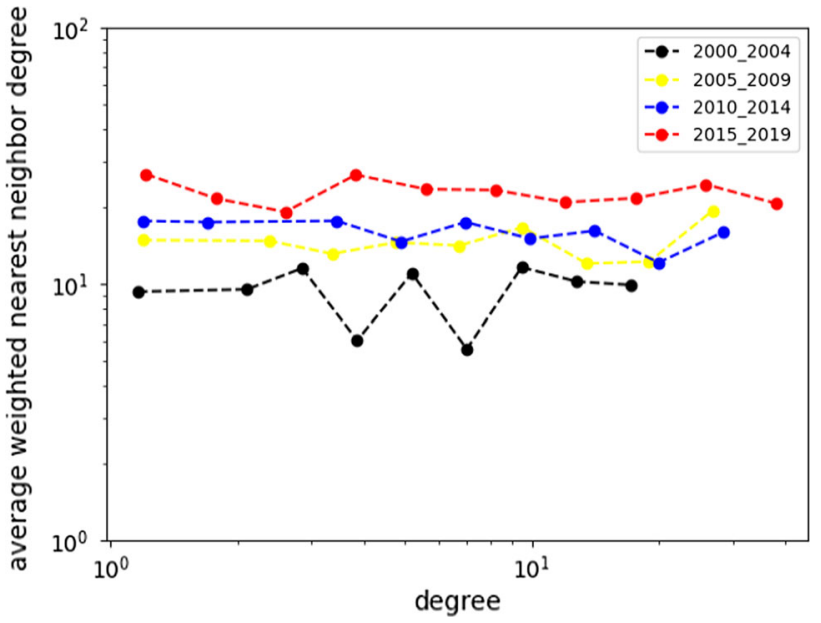

Fig. 6 Average weighted nearest-neighbor degree of $\mathrm{KCN}$ keywords for the manufacturing science and engineering literature

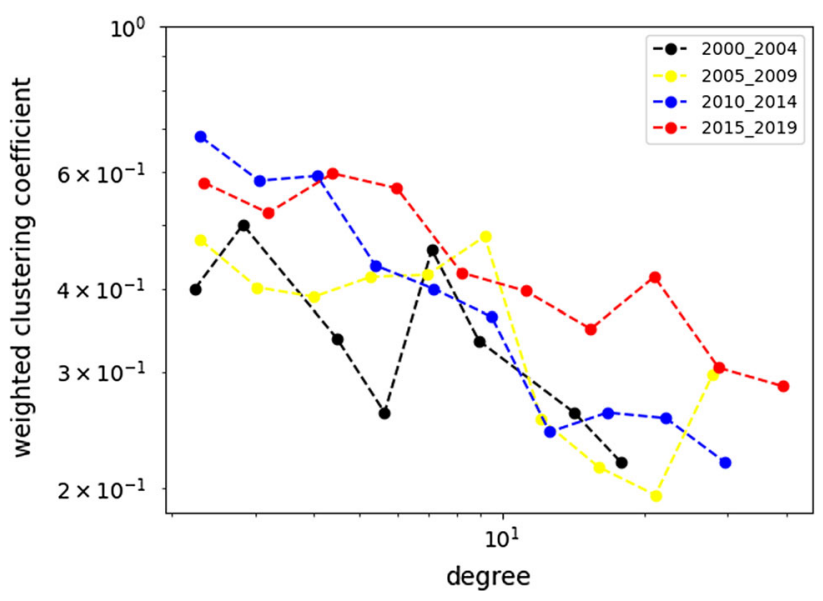

Fig. 7 Weighted clustering coefficient of $\mathrm{KCN}$ keywords for the manufacturing science and engineering literature

show an overall behavior similar to that of a structural organization of networks. Exponential growth in average weighted end point degree indicates that keyword pairs with higher degrees co-occur more frequently. Flat patterns in the average weighted nearest neighbor degree show that there is no clear tendency of low degree nodes attaching to low degree nodes. That is, there is a pattern of less frequently used keywords co-occurring with other less frequently used keywords. Lastly, the average weighted clustering coefficients explain the existence of edges between high degree anfd low degree keywords.

\section{Discussion}

From 2000 to 2019, the number of articles published in the field of manufacturing has increased fivefold, but the number of keywords has increased by only $68 \%$. Though the 
manufacturing literature has grown considerably in volume, it has not seen proportional growth in the variety of keywords, indicating that new topics have been introduced at a much slower pace than the growth of the body of manufacturing knowledge. In other words, some keywords remained active over the two-decade period. The new keywords in the literature emerged from research articles on intelligent and cyber manufacturing, which experienced a rapid expansion, and the research in this field experience a period of innovation. While the keywords grew by two-thirds, the connections between the keywords have tripled, implying that manufacturing research is moving toward the convergence of different topics.

Although the size of KCNs increased steadily over four periods, the average weight changed only slightly. This pattern indicates that the topology of the manufacturingkeyword co-occurrence network is a small world. The skewed weight distribution and clustering coefficients illustrate that most keywords have a low degree, and most links have a low weight. In other words, the networks have a small number of keywords with a high degree and only a few links with large weights. This node degree and link weight pattern might be due to the tendency of researchers to pick oftenused keywords in their papers relative to less frequently used keywords. This could also be due to the possibility that only a small select set of keywords tend to be widely discussed in literature.

In the manufacturing literature, we observe only a few keywords (e.g., genetic algorithm, optimization, neural networks, industry 4.0) co-occur with many other keywords, but a large number of keywords co-occur with only a small set of other keywords. High-degree keywords (e.g., genetic algorithm, optimization, fault diagnosis, heuristics) tend to link up with not only other high-degree keywords but also with low-degree keywords. The less frequently (e.g., mobile robot, predictive maintenance, $k$-means clustering) occurring keywords tend to appear as part of only a few keyword groups, but most frequently occurring words (e.g., genetic algorithm, optimization, heuristics, fault diagnosis, data mining) cooccur with keywords positioned in a wide variety of keyword groups. This observation implies that the most frequently used manufacturing keywords are associated with a diverse set of research tracks in manufacturing. That is to say, the keyword hubs (popular keywords such as genetic algorithm, optimization) occur in articles covering diverse topics. Five keywords-genetic algorithm, optimization, heuristics, fault diagnosis, data mining - are the most frequently used keywords across all four time windows in two decades. Machine learning, Industry 4.0, big data, cloud manufacturing, and deep learning are the emerging keywords indicating the dawn of cyber manufacturing. These observations inform future manufacturing research, technology trends. This could also inform knowledge and skills needs of intelligent manufacturing workforce, which has been experiencing high demand.

Influenced by Industry 4.0, cyber-physical manufacturing technologies grew more complex and more knowledgeintensive. Cyber technologies, over the last five years, have expanded and enriched the body of the literature, which was principally composed by the physical technologies in the early twentieth century. Methods with growing popularity can be grouped into three categories: data science (machine learning, deep learning, and big data), cloud-based technologies (cloud computing and internet of things), and cyber-physical technologies (augmented reality and digital twins). As the research in physical manufacturing dwindled, the research focus shifted to the emerging cyber technologies that enhance the performance and efficiency of manufacturing machines, equipment, and systems; and this trend is expected to continue in the future.

From the topological characteristics of $\mathrm{KCNs}$, it is observed that the connectivity among keywords has enhanced with time, from 2000 to 2019. The network hubs represent versatile and perennial technologies such as genetic algorithm, optimization, fault diagnosis, and neural networks. While some keywords have more cohesiveness in the first decade, that is not the case in the second decade during which keywords tend to connect with a variety of emerging topics. This indicates that researchers, in the last decade, were trying to explore the synergies among various topics instead of focusing on only a run-of-the-mill topic. The convergence of different areas has become a trend with time. Overall, the community of cyber-physical manufacturing has proliferated, and research is moving toward greater convergence.

One of the important goals of this paper is to identify the specific domain knowledge associated with emerging intelligent and cyber manufacturing technologies. The nine pillars of Industry 4.0 (Vaidya et al., 2018) are utilized as a reference to categorize and organize the keywords, as shown in Fig. 8. The top 50 most frequently used keywords (ranked based on their strength) in 2015-2019 on the left side are subjectively mapped to one or multiple pillars of Industry 4.0 on the right side. Based on the authors' subjective evaluations, "Autonomous Robots", "Internet of Things", and "Big data" are the top three pillars with the highest number of connections with research keywords, which indicates their popularity in the research area and their role in informing the technology trends in intelligent manufacturing. The mapping identifies the specific domain knowledge associated with emerging intelligent and cyber manufacturing technologies and can inform the design and development of new curricula for the future manufacturing workforce. The number of links to the nine Industry 4.0 pillars indicate the relevance of the topics (high-requency keywords) in their respective areas. The keywords linked to the pillars suggest possible topics to be covered in those courses. 


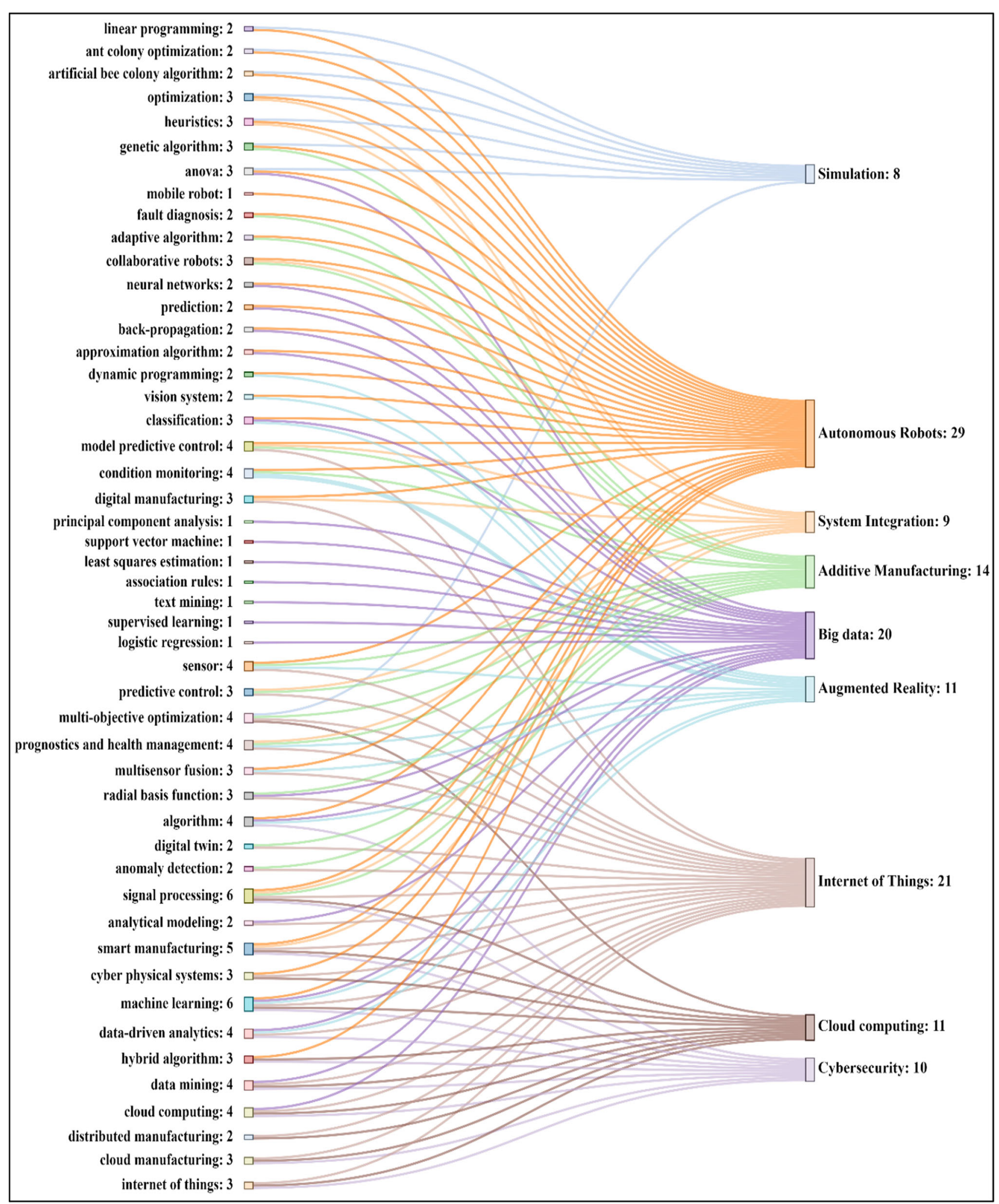

Fig. 8 Subjective mapping between the top 50 keywords ranked based on their strength (left) and the nine pillars of Industry 4.0 (right). The number next to the keyword indicate the number of keywords from the other side are connected to it 
One of our recent studies analyzes the data science and analytics skills gap in today's manufacturing workforce ( $\mathrm{Li}$ et al., 2021). The gap analysis was conducted on a comprehensive labor market analytics data, (i.e., Emsi) which contains job posting and profile data providing insights into the trends and potential of high in-demand skills for future manufacturing jobs. By connecting it with this work, it is noticed that major domain knowledge gaps existing in data science-related jobs are machine learning, big data analytics, data mining and optimization, which are aligned with the emerging topics in manufacturing research. The trend of research focus shifted to the emerging cyber technologies which enhance the performance and efficiency of manufacturing machines, equipment, and systems. It is also reflected in the U.S. labor market which has experienced $8 \%$ growth in the total number of job postings related to cyber technologies in 2020 ..

\section{Conclusions}

This paper conducted a keyword co-occurrence network analysis of intelligent and cyber manufacturing-related keywords in the scientific 84,041 papers published in top-tier manufacturing journals during the period between 2000 and 2019. The analysis reveals insight into knowledge structures of the manufacturing field and the evolution of research themes for the past two decades. To analyze keywords in all publications, we built a network of keywords that are relevant to the broader areas of intelligence and cyber manufacturing. The statistical analysis of network characteristics effectively analyzes the trends and patterns in research topics (e.g., cloud manufacturing, data mining, and machine learning as applied to manufacturing) over time. Traditional literature review methods discuss key features of technical methods, general methodologies, and experimental findings. In contrast, the KCN-based approach gives a macro-level understanding of research trends and the evolution of emerging technologies. It enables macro-level quantitative analysis and in-depth, comprehensive reviews with less manual effort. This approach can be readily applied to understand other scientific fields macroscopically.

The analysis of only keywords to observe the knowledge structure and trends can lead to some biases. For example, some authors may not include an important term in the keyword section, but it otherwise plays a significant role in the subject of the paper. Future work will extract words from the title and abstract to enrich the keywords database to better reveal the keywords correlation in the body of knowledge. The keyword co-occurrence network-based methodology can also potentially benefit from extensive text mining and natural language processing of published arti- cles to capture more in-depth insights into the scientific and technological trends in intelligent and cyber manufacturing.

This work identified the high-frequency keyworkds associated with the nine pillars of Industry 4.0, namely simulation, autonomous robots, system integration, additive manufacturing, big data, augmented reality, IoT, cloud computing, and cybersecurity. These keywords suggeste the possible topics for future research and education in intelligent manufacturing.

Acknowledgements This material is based upon work supported by the National Science Foundation under Grant No. 1935646. Any opinions, findings, and conclusions, or recommendations expressed in this material are those of the author(s) and do not necessarily reflect the views of the National Science Foundation.

Funding National Science Foundation (Grant No.1935646) funded by Sagar Kamarthi

Open Access This article is licensed under a Creative Commons Attribution 4.0 International License, which permits use, sharing, adaptation, distribution and reproduction in any medium or format, as long as you give appropriate credit to the original author(s) and the source, provide a link to the Creative Commons licence, and indicate if changes were made. The images or other third party material in this article are included in the article's Creative Commons licence, unless indicated otherwise in a credit line to the material. If material is not included in the article's Creative Commons licence and your intended use is not permitted by statutory regulation or exceeds the permitted use, you will need to obtain permission directly from the copyright holder. To view a copy of this licence, visit http://creativecomm ons.org/licenses/by/4.0/.

\section{References}

Aggour, K. S., et al. (2019). Artificial intelligence/machine learning in manufacturing and inspection: A GE perspective. MRS Bulletin, 44(7), 545-558. https://doi.org/10.1557/mrs.2019.157

Alam, K. M., \& El Saddik, A. (2017). C2PS: A digital twin architecture reference model for the cloud-based cyber-physical systems. IEEE Access, 5, 2050-2062. https://doi.org/10.1109/ACCESS. 2017.2657006

Alcácer, V., \& Cruz-Machado, V. (2019). Scanning the Industry 4.0: A Literature review on technologies for manufacturing systems. Engineering Science and Technology, an International Journal, 22(3), 899-919. https://doi.org/10.1016/j.jestch.2019.01.006

Barari, A., de Sales Guerra, M., Tsuzuki, Y. C., \& Macchi, M. (2021). Editorial: intelligent manufacturing systems towards industry 4.0 era. Journal of Intelligent Manufacturing. https://doi.org/10.1007/ s10845-021-01769-0

Baroroh, D. K., Chu, C.-H., \& Wang, L. (2020). Systematic literature review on augmented reality in smart manufacturing: Collaboration between human and computational intelligence. Journal of Manufacturing Systems. https://doi.org/10.1016/j.jmsy.2020. 10.017

Barrat, A., Barthélemy, M., Pastor-Satorras, R., \& Vespignani, A. (2004). The architecture of complex weighted networks. Proceedings of the National Academy of Sciences, 101(11), 3747-3752. https://doi.org/10.1073/pnas.0400087101 
Chen, T. C. T. (2017). Cloud intelligence in manufacturing. Journal of Intelligent Manufacturing, 28(5), 1057-1059. https://doi.org/10. 1007/s10845-015-1122-9

Choudhary, A. K., Harding, J. A., \& Tiwari, M. K. (2009). Data mining in manufacturing: A review based on the kind of knowledge. Journal of Intelligent Manufacturing, 20(5), 501-521. https://doi. org/10.1007/s10845-008-0145-x

Cui, Y., Kara, S., \& Chan, K. C. (2020). Manufacturing big data ecosystem: A systematic literature review. Robotics and ComputerIntegrated Manufacturing, 62, 101861. https://doi.org/10.1016/j. rcim.2019.101861

$\mathrm{Da} \mathrm{Xu}, \mathrm{L} ., \mathrm{He}, \mathrm{W} .$, \& Li, S. (2014). Internet of things in industries: A survey. IEEE Transactions on Industrial Informatics, 10(4), 2233-2243. https://doi.org/10.1109/TII.2014.2300753

De Felice, F., Petrillo, A., \& Zomparelli, F. (2018). A bibliometric multicriteria model on smart manufacturing from 2011 to 2018. IFAC-PapersOnLine, 51(11), 1643-1648. https://doi.org/10.1016/ j.ifacol.2018.08.221

Duvvuru, A., Kamarthi, S., \& Sultornsanee, S. (2012). Undercovering research trends: Network analysis of keywords in scholarly articles. In 2012 Ninth International Conference on Computer Science and Software Engineering (JCSSE) (pp. 265-270). IEEE.

Escobar, C. A., McGovern, M. E., \& Morales-Menendez, R. (2021). Quality 4.0: a review of big data challenges in manufacturing. Journal of Intelligent Manufacturing, 1-16.

Franco, D., Miller Devós Ganga, G., de Santa-Eulalia, L. A., \& Godinho Filho, M. (2020). Consolidated and inconclusive effects of additive manufacturing adoption: A systematic literature review. Computers \& Industrial Engineering, 148, 106713. https://doi.org/ 10.1016/j.cie.2020.106713

Henzel, R., \& Herzwurm, G. (2018). Cloud Manufacturing: A stateof-the-art survey of current issues. Procedia CIRP, 72, 947-952. https://doi.org/10.1016/j.procir.2018.03.055

Hofmann, E., \& Rüsch, M. (2017). Industry 4.0 and the current status as well as future prospects on logistics. Computers in Industry, 89, 23-34. https://doi.org/10.1016/j.compind.2017.04.002

Järvenpää, E., Siltala, N., Hylli, O., \& Lanz, M. (2019). The development of an ontology for describing the capabilities of manufacturing resources. Journal of Intelligent Manufacturing, 30(2), 959-978. https://doi.org/10.1007/s10845-018-1427-6

Kusiak, A. (2018). Smart manufacturing. International Journal of Production Research, 56(1-2), 508-517. https://doi.org/10.1080/ 00207543.2017.1351644

Kusiak, A. (2019). Editorial: Intelligent manufacturing: Bridging two centuries. Journal of Intelligent Manufacturing, 30(1), 1-2. https:// doi.org/10.1007/s10845-018-1455-2

Kutschenreiter-Praszkiewicz, I. (2008). Application of artificial neural network for determination of standard time in machining. Journal of Intelligent Manufacturing, 19(2), 233-240. https://doi.org/10. 1007/s10845-008-0076-6

Li, G., Yuan, C., Kamarthi, S., Moghaddam, M., \& Jin, X. (2021). Data science skills and domain knowledge requirements in the manufacturing industry: A gap analysis. Journal of Manufacturing Systems. https://doi.org/10.1016/j.jmsy.2021.07.007

Li, H., An, H., Wang, Y., Huang, J., \& Gao, X. (2016). Evolutionary features of academic articles co-keyword network and keywords co-occurrence network: Based on two-mode affiliation network. Physica A: Statistical Mechanics and its Applications, 450, 657-669. https://doi.org/10.1016/j.physa.2016.01.017

Lozano, S., Calzada-Infante, L., Adenso-Díaz, B., \& García, S. (2019). Complex network analysis of keywords co-occurrence in the recent efficiency analysis literature. Scientometrics, 120(2), 609-629. https://doi.org/10.1007/s11192-019-03132-w

Lu,Y., Morris, K. C., \& Frechette, S. (2016). Current standards landscape for smart manufacturing systems, National Institute of Standards and Technology, NISTIR, Vol. 8107, p. 39.
Majstorović, V. D. et al. (2018) Cyber-physical manufacturing in context of industry 4.0 model. In Lecture Notes in Mechanical Engineering, vol. 0, no. 9783319895628, Pleiades Publishing, pp. 227-238.

Miškuf, M., \& Zolotová, I. (2016). Comparison between multi-class classifiers and deep learning with focus on industry 4.0. In 2016 Cybernetics \& Informatics (K\&I) (pp. 1-5). IEEE.

Moghaddam, M., Cadavid, M. N., Kenley, C. R., \& Deshmukh, A. V. (2018). Reference architectures for smart manufacturing: A critical review. Journal of Manufacturing Systems. https://doi.org/10. 1016/j.jmsy.2018.10.006

Moghaddam, M., Cadavid, M. N., Kenley, C. R., \& Deshmukh, A. V. (2018). Reference architectures for smart manufacturing: A critical review. Journal of Manufacturing Systems, 49, 215-225. https:// doi.org/10.1016/j.jmsy.2018.10.006

Moghaddam, M., \& Nof, S. Y. (2017). The collaborative factory of the future. International Journal of Computer Integrated Manufacturing, 30(1), 23-43. https://doi.org/10.1080/0951192X.2015. 1066034

Monostori, L., et al. (2016). Cyber-physical systems in manufacturing. CIRP Annals-Manufacturing Technology, 65(2), 621-641. https://doi.org/10.1016/j.cirp.2016.06.005

Mourtzis, D., Vlachou, E., \& Milas, N. (2016). Industrial big data as a result of IoT adoption in manufacturing. Procedia CIRP, 55, 290-295. https://doi.org/10.1016/j.procir.2016.07.038

Nguyen Ngoc, H., Lasa, G., \& Iriarte, I. (2021). Human-centred design in industry 4.0: case study review and opportunities for future research. Journal of Intelligent Manufacturing. https://doi.org/10. 1007/s10845-021-01796-x

Nti, I. K., Adekoya, A. F., Weyori, B. A., \& Nyarko-Boateng, O. (2021). Applications of artificial intelligence in engineering and manufacturing: A systematic review. Journal of Intelligent Manufacturing . https://doi.org/10.1007/s10845-021-01771-6

NWB Team. (2006). Network Workbench Tool. Indiana University, Northeastern University, and University of Michigan. http://nwb. slis.indiana.edu.

Onel, S., Zeid, A., \& Kamarthi, S. (2011). The structure and analysis of nanotechnology co-author and citation networks. Scientometrics. https://doi.org/10.1007/s11192-011-0434-6

Ooi, K. B., Lee, V. H., Tan, G. W. H., Hew, T. S., \& Hew, J. J. (2018). Cloud computing in manufacturing: The next industrial revolution in Malaysia? Expert Systems with Applications, 93, 376-394. https://doi.org/10.1016/j.eswa.2017.10.009

Oztemel, E., \& Gursev, S. (2020). Literature review of industry 4.0 and related technologies. Journal of Intelligent Manufacturing, 31(1), 127-182. https://doi.org/10.1007/s10845-018-1433-8

Radhakrishnan, S., Erbis, S., Isaacs, J. A., \& Kamarthi, S. (2017). Novel keyword co-occurrence network-based methods to foster systematic reviews of scientific literature. PLoS ONE, 12(3), 1-16. https:// doi.org/10.1371/journal.pone.0172778

Rajkumar, R., Lee, I., Sha, L., Stankovic, J. (2010) Cyber-physical systems: The next computing revolution. In Proceedings-design automation conference, pp. 731-736, doi: https://doi.org/10.1145/ 1837274.1837461.

Recommendations for implementing the strategic initiative INDUSTRIE 4.0 April 2013 Securing the future of German manufacturing industry Final report of the Industrie 4.0 Working Group.

Schuh, G., Anderl, R., Gausemeier, J., ten Hompel, M., \& Wahlster, W. (2017). Industrie 4.0 maturity index. Munich: Herbert Utz.

Shibata, N., Kajikawa, Y., Takeda, Y., Sakata, I., \& Matsushima, K. (2011). Detecting emerging research fronts in regenerative medicine by the citation network analysis of scientific publications. Technological Forecasting and Social Change, 78(2), 274-282. https://doi.org/10.1016/j.techfore.2010.07.006

Shrouf, F., Ordieres, J. Miragliotta, G. (2014) Smart factories in Industry 4.0: A review of the concept and of energy manage- 
ment approached in production based on the Internet of Things paradigm. In IEEE international conference on industrial engineering and engineering management, vol. 2015, pp. 697-701, doi: https://doi.org/10.1109/IEEM.2014.7058728.

Su, H. N., \& Lee, P. C. (2010). Mapping knowledge structure by keyword co-occurrence: A first look at journal papers in Technology Foresight. Scientometrics, 85(1), 65-79. https://doi.org/10.1007/ s11192-010-0259-8

Thoben, K.-D., Wiesner, S., \& Wuest, T. (2017). 'Industrie 4.0' and smart manufacturing-A review of research issues and application examples. International Journal of Automation Technology, 11(1), 4-16. https://doi.org/10.20965/ijat.2017.p0004

Tian, G. Y., Yin, G., \& Taylor, D. (2002). Internet-based manufacturing: A review and a new infrastructure for distributed intelligent manufacturing. Journal of Intelligent Manufacturing, 13(5), 323-338. https://doi.org/10.1023/A:1019907906158

Usuga Cadavid, J. P., Lamouri, S., Grabot, B., Pellerin, R., \& Fortin, A. (2020). Machine learning applied in production planning and control: a state-of-the-art in the era of industry 4.0. Journal of Intelligent Manufacturing, 31(6), 1531-1558. https://doi.org/10. 1007/s 10845-019-01531-7

Vaidya, S., Ambad, P., \& Bhosle, S. (2018). Industry 4.0-A glimpse. Procedia Manufacturing, 20, 233-238. https://doi.org/10.1016/j. promfg.2018.02.034
Xu, X. (2012). From cloud computing to cloud manufacturing. Robotics and Computer-Integrated Manufacturing, 28(1), 75-86. https:// doi.org/10.1016/J.RCIM.2011.07.002

Yao, X., Zhou, J., Lin, Y., Li, Y., Yu, H., \& Liu, Y. (2019). Smart manufacturing based on cyber-physical systems and beyond. Journal of Intelligent Manufacturing, 30(8), 2805-2817. https://doi.org/10. 1007/s10845-017-1384-5

Zhong, W., An, H., Gao, X., \& Sun, X. (2014). The evolution of communities in the international oil trade network. Physica A: Statistical Mechanics and its Applications, 413, 42-52. https://doi.org/10. 1016/j.physa.2014.06.055

Publisher's Note Springer Nature remains neutral with regard to jurisdictional claims in published maps and institutional affiliations. 